\title{
FAKTOR-FAKTOR YANG BERHUBUNGAN DENGAN KECELAKAAN KERJA PADA PEKERJA PROYEK PEMBANGUNAN GEDUNG DI PT. X TAHUN 2020
}

\author{
Nikhmatul Huda ${ }^{{ }^{*}}$, Azizah Musliha Fitri ${ }^{1}$, Arga Buntara ${ }^{1}$, Dyah Utari ${ }^{1}$ \\ ${ }^{1}$ Peminatan Keselamatan dan Kesehatan Kerja - Kesehatan Lingkungan, \\ Fakultas Ilmu Kesehatan, Universitas Pembangunan Nasional Veteran Jakarta \\ ${ }^{*}$ Corresponding author: nikhmatulhuda10@gmail.com
}

\begin{abstract}
The construction sector is ranked first as the most dangerous occupation in the world and is an area with a high risk of occupational accidents. According to BPJS Ketenagakerjaan data in 2019, cases of work accidents in Indonesia 2017 increased in 2018. The purpose of this study was to determine the relationship between age, OHS knowledge, OHS supervision, unsafe act, and unsafe condition for building construction project workers at PT. X. This research was quantitative study with a crosssectional study design. The sampling technique used simple random sampling where the sample amounted to 109 workers. The results of the research analysis using the chi-square statistical test showed that the variables of age ( $p$-value $=0,662)$, OHS knowledge ( $p$-value 0,003$)$, OHS supervision ( $p$-value 0,001$)$, unsafe act ( $p$-value 0,002$)$, unsafe condition ( $p$-value 0,000$)$ with a significance limit of $\alpha=0,05$. It can be concluded that there is an associated between OHS knowledge, OHS supervision, unsafe act, and unsafe condition with work accidents and there is no associated between age with work accidents. It is recommended that companies provide education to workers in the form of providing OHS knowledge through the toolbox meeting program and periodically monitoring of conditions in the work field.
\end{abstract}

Keywords: Work Accidents, Workers, Construction

\section{PENDAHULUAN}

Keselamatan dan Kesehatan Kerja merupakan bagian penting dalam mendorong produktivitas dan kinerja para pekerja, namun di sektor konstruksi budaya kerja K3 belum maksimal pada pelaksanaannya sebab kurangnya kesadaran akan pentingnya bekerja dengan berpedoman K3. Direktur Bina Penyelenggaraan Jasa Konstruksi Kementerian PUPR, Ir. Sumito tahun 2018 mengatakan bahwa hal ini terlihat dari terjadinya kecelakaan konstruksi dalam pembangunan infrastruktur Indonesia diantaranya beton terlepas dari crane proyek LRT Jakarta dan JPO runtuh proyek jalan tol Bogor-Ciawi-Sukabumi ${ }^{1}$.

Menurut data Kementerian PUPR tahun 2018, dalam kurun waktu dua tahun terakhir telah terjadi empat belas kasus kecelakaan kerja di proyek konstruksi. Ada empat kasus kecelakaan kerja pada konstruksi layang (elevated) terjadi di DKI Jakarta dalam tiga sampai empat bulan awal tahun $2018{ }^{2}$. Sebesar $32 \%$ dari kasus kecelakaan kerja yang terjadi di Indonesia sepanjang tahun 2017, merupakan kecelakaan kerja di sektor konstruksi ${ }^{3}$.

Sektor konstruksi adalah bidang dengan risiko kecelakaan kerja yang cukup tinggi ${ }^{4}$. Ini terjadi karena lokasi kerja yang tidak hanya satu titik, dipengaruhi suhu dan cuaca sebab di lingkungan terbuka, memiliki jangka waktu pelaksanaan, harus memiliki daya fisik yang cukup tinggi, serta kebanyakan pekerja tidak terlatih (hanya mengandalkan kekuatan fisik) ${ }^{5}$.

Sektor konstruksi berada di peringkat pertama sebagai pekerjaan paling berbahaya di dunia ${ }^{6}$. Berbagai pekerjaan yang terbilang paling berbahaya adalah bekerja di ketinggian dan bekerja di dalam galian. Kecelakaan kerja acapkali berdampak fatal pada kedua jenis pekerjaan tersebut. Sebagai gambaran, pekerja yang mengerjakan proyek konstruksi di ketinggian tanpa menggunakan pengaman berisiko jatuh sehingga dapat menyebabkan kematian ${ }^{7}$.

Menurut data perkiraan global yang dirilis International Labour Organization (ILO) pada tahun 2017, setiap tahun sebanyak 2,78 juta pekerja meninggal dikarenakan kecelakaan di tempat kerja dan penyakit akibat kerja. Diantaranya 2,4 juta pekerja $(86,3 \%)$ meninggal terkait penyakit akibat kerja dan 380.000 pekerja (13,7\%) meninggal akibat kecelakaan kerja ${ }^{8}$. Kasus ini menunjukkan peningkatan secara keseluruhan dalam jumlah kematian akibat pekerjaan yakni pada tahun 2014 angka kematian 2,33 juta naik tahun 2017 menjadi 2,78 juta angka kematian ${ }^{9}$.

Menurut data BPJS Ketenagakerjaan, tercatat angka kecelakaan kerja di Indonesia tahun 2017 yaitu 123.041 kasus. Namun 


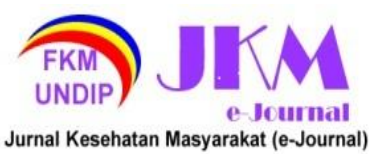

angka kecelakaan kerja meningkat tahun 2018 hingga mencapai 173.105 kasus ${ }^{10}$.

Tarwaka (2012) menyebutkan bahwa kecelakaan kerja merupakan terjadinya hal yang tidak diinginkan, terjadi tiba-tiba dan mengakibatkan kerugian material, kehilangan waktu bahkan kehilangan nyawa. Tidak amannya lingkungan kerja dan human error menjadi penyebab kecelakaan di tempat kerja 11.

Banyak faktor yang memengaruhi terjadinya kecelakaan kerja. Menurut Notoatmodjo (2003), kecelakaan kerja terjadi karena faktor karakteristik dari pekerjanya sendiri seperti kurangnya kemampuan yang dimiliki, kelelahan karena jam kerja berlebihan, proses rekrutmen pekerja yang salah, dan pengawasan yang kurang ${ }^{12}$. Kecelakaan kerja juga terjadi karena lingkungan kerja yang tidak sesuai standar, perlengkapan dan peralatan yang digunakan saat bekerja, Alat Pelindung Diri (APD) yang tidak tersedia, tingkat pengetahuan mengenai K3 dan Pedoman Operasional Baku (POB) yang minim ${ }^{13}$.

Menurut H. W. Heinrich, sebesar $88 \%$ kasus kecelakaan di tempat kerja terjadi karena adanya tindakan tidak aman (unsafe action), 10\% kecelakaan kerja terjadi karena kondisi tidak aman (unsafe condition) dan sisanya terjadi karena kesalahan manusia itu sendiri. Unsafe action dan unsafe condition akan terjadi jika manusia melakukan kesalahan ${ }^{14}$.

PT. X adalah perusahaan yang bergerak di sektor konstruksi. Saat ini, perusahaan tersebut menjadi kontraktor pada proyek pembangunan gedung di daerah Jakarta Pusat. Dalam proses pekerjaan proyek, banyak alat berat, mesin-mesin maupun peralatan kerja yang berpotensi membahayakan pekerja hingga menyebabkan terjadinya kecelakaan di lingkungan kerja. Dari pernyataan yang sudah disampaikan di atas, peneliti ingin melakukan suatu penelitian yang memiliki tujuan untuk mengetahui faktor-faktor yang berhubungan dengan terjadinya kecelakaan kerja pada pekerja proyek pembangunan gedung di PT. X.

\section{METODE PENELITIAN}

Penelitian ini merupakan penelitian kuantitatif dengan menggunakan desain studi cross-sectional. Dilakukan pada November 2020-Januari 2021. Sampel diperoleh 109 orang dari perhitungan rumus slovin dengan populasi penelitian berjumlah 150 orang. Cara untuk melakukan pemilihan sampel yaitu menggunakan teknik probability sampling dengan metode simple random sampling. Pengumpulan data didapatkan dari data primer yaitu wawancara langsung menggunakan kuesioner dan pengamatan menggunakan lembar ceklis observasi hasil modifikasi dari beberapa penelitian terdahulu. Selain itu juga didapatkan dari data sekunder yaitu beberapa arsip perusahaan yang mendukung penelitian.

Data yang telah dikumpulkan selanjutnya diolah dan dianalisis. Analisis univariat dilakukan untuk memperoleh gambaran distribusi frekuensi semua variabel penelitian serta analisis bivariat menggunakan uji statistik chi-square dilakukan untuk membuktikan hipotesis awal penelitian yaitu mengetahui adanya hubungan variabel independen dengan variabel dependen. Hasil analisis data disajikan dalam bentuk tabel dan narasi. Penelitian ini dilakukan dengan memperhatikan etika dalam penelitian dan sudah mendapatkan persetujuan etik dari Komisi Etik Penelitian Kesehatan (KEPK) Universitas Pembangunan Nasional Veteran Jakarta dengan nomor 2852/XII/2020/KEPK.

HASIL

\section{Analisis Univariat}

Distribusi frekuensi seluruh variabel penelitian dapat dilihat dari sajian tabel 1 berikut:

Tabel 1. Analisis Univariat pada Pekerja Proyek Pembangunan Gedung di PT. X Tahun 2020

\begin{tabular}{lcc}
\multicolumn{1}{c}{ Variabel } & Frekuensi (N) & Persentase (\%) \\
\hline Kecelakaan Kerja & 68 & 62,4 \\
Pernah & 41 & 37,6 \\
Tidak Pernah & 73 & 67 \\
Usia & 36 & 33 \\
Muda (<35 tahun) & & \\
Tua ( $\geq 35$ tahun) & 61 & 56 \\
Pengetahuan K3 & 48 & 44 \\
Rendah & &
\end{tabular}




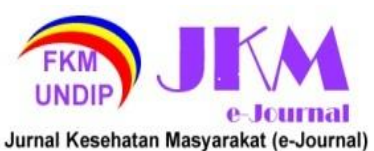

\section{Pengawasan K3}

Rendah

Tinggi

Unsafe Act

Tindakan Tidak Aman

Tindakan Aman

Unsafe Condition

Kondisi Tidak Aman

Kondisi Aman
JURNAL KESEHATAN MASYARAKAT (e-Journal)

Volume 9, Nomor 5, September 2021

ISSN: 2715-5617 / e-ISSN: 2356-3346

http://ejournal3.undip.ac.id/index.php/jkm
Berdasarkan tabel 1 , hasil penelitian analisis univariat menunjukkan sebagian besar pekerja $(62,4 \%)$ pernah mengalami kasus kecelakaan kerja. Kebanyakan pekerja $(67 \%)$ berada pada usia muda yaitu berusia kurang dari 35 tahun, mayoritas pekerja (56\%) memiliki pengetahuan yang rendah terkait $\mathrm{K} 3$, lebih dari separuh pekerja $(51,4 \%)$ memiliki
56

53

51,4

54

49,5

55

50,5

54

49,5

50,5

Tabel 2. Analisis Bivariat Faktor-Faktor yang Berhubungan dengan Kecelakaan Kerja

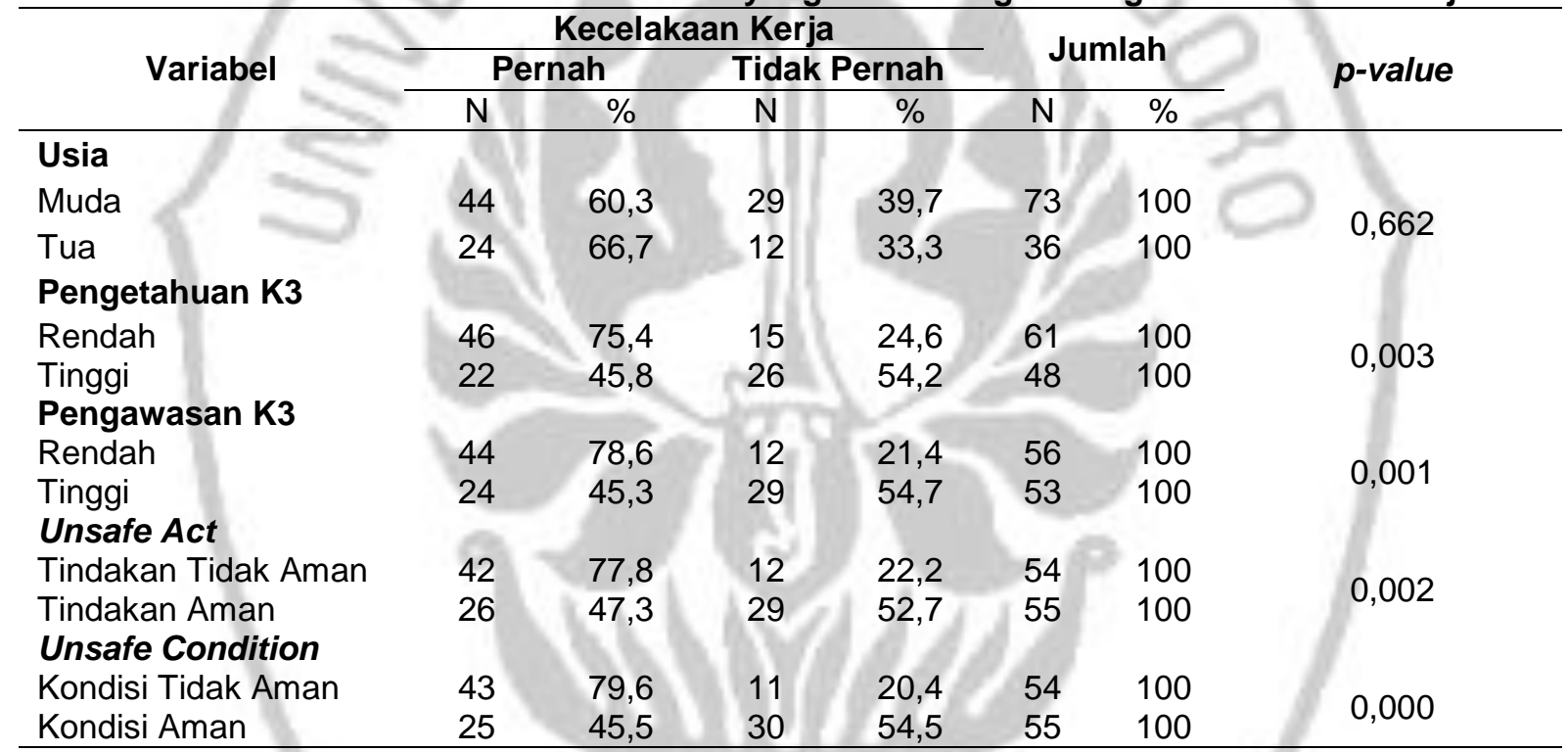

Berdasarkan tabel 2, hasil penelitian analisis bivariat hubungan usia dengan kecelakaaan kerja menunjukkan kejadian kecelakaan kerja paling banyak dialami oleh pekerja yang berusia tua $(66,7 \%)$ dibandingkan dengan pekerja yang berusia muda $(60,3 \%)$. Didapatkan $p$-value $0,662(p>$ $0,05)$ sehingga Ho diterima. Dapat disimpulkan tidak ada hubungan antara usia dengan kecelakaan kerja pada pekerja.

Hubungan pengetahuan K3 dengan kecelakaan kerja menunjukkan bahwa kecelakaan kerja mayoritas dialami para pekerja yang memiliki pengetahuan rendah terkait K3 yaitu sebanyak 46 orang $(75,4 \%)$ daripada pekerja berpengetahuan tinggi. Didapatkan $p$-value $0,003(p<0,05)$ sehingga persepsi pengawasan $\mathrm{K} 3$ yang rendah, hampir separuh dari pekerja (49,5\%) melakukan tindakan tidak aman pada saat bekerja dan bekerja pada kondisi tidak aman.

\section{Analisis Bivariat}

Hasil analisis bivariat penelitian dapat dilihat dari sajian tabel 2 berikut: 


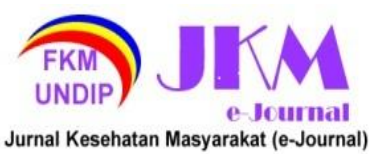

pekerja yang bertindak tidak aman saat bekerja yaitu sebanyak 42 orang $(77,8 \%)$ dibandingkan dengan pekerja yang bekerja dengan tindakan aman. Didapatkan $p$-value $0,002(p<0,05)$ sehingga Ho ditolak. Dapat disimpulkan ada hubungan antara tindakan tidak aman dengan kecelakaan kerja pada pekerja.

Hubungan unsafe condition dengan kecelakaan kerja menunjukkan bahwa kejadian kecelakaan kerja paling banyak dialami oleh pekerja yang bekerja pada kondisi tidak aman yaitu sebanyak 43 orang $(79,6 \%)$ dibandingkan dengan pekerja yang bekerja pada kondisi aman. Didapatkan $p$-value 0,000 $(p<0,05)$ sehingga Ho ditolak. Dapat disimpulkan ada hubungan antara kondisi tidak aman dengan kecelakaan kerja pada pekerja.

\section{PEMBAHASAN}

Kecelakaan Kerja pada Pekerja Proyek Pembangunan Gedung di PT. $X$

Penelitian yang telah dilakukan pada pekerja proyek pembangunan gedung di PT. X tahun 2020 diperoleh hasil bahwa sebanyak 68 orang pekerja $(62,4 \%)$ pernah mengalami kecelakaan kerja sedangkan 41 orang pekerja lainnya $(37,6 \%)$ tidak pernah mengalami kecelakaan kerja. Dari hasil penelitian tersebut mayoritas dari pekerja proyek pernah mengalami kasus kecelakaan kerja dan angka kecelakaan yang pernah terjadi tergolong masih tinggi.

Tersayat / tergores merupakan bentuk kecelakaan kerja yang paling kerap kali dialami oleh pekerja, lalu diikuti oleh tersandung, tertusuk paku, terpeleset dan terperosok. Semua kasus kecelakaan kerja tersebut tidak sampai mengakibatkan kejadian yang fatal karena jenis kecelakaan kerja yang terjadi masih dalam kategori ringan. Meskipun kecelakaan kerja masih masuk golongan ringan, perusahaan tidak boleh abai dan sebaiknya tetap menjadi fokus utama untuk selalu berupaya menjaga keselamatan para pekerja karena jika diabaikan maka kasus kecelakaan ini mungkin akan jauh lebih berat dan serius.

\section{Hubungan antara Usia dengan Kecelakaan Kerja}

Hasil pada penelitian ini sesuai dengan penelitian Juliana, Purna dan Aryana pada tahun 2018 yaitu tidak ada hubungan antara umur dengan kejadian kecelakaan kerja karena $p$-value 0,301 ( $p>0,05)$. Berdasarkan penelitian tersebut, disebutkan bahwa selisih angka kecelakaan kerja pada usia muda dan usia tua tidak terlalu jauh berbeda, yaitu sebesar $58,7 \%$ untuk usia tua yang pernah kecelakaan kerja dan $58,3 \%$ untuk usia muda yang pernah kecelakaan kerja ${ }^{15}$.

Namun penelitian ini tidak sesuai dengan penelitian Handayani, Wibowo \& Suryani pada tahun 2010 menggunakan analisis regresi dan korelasi diperoleh $p$-value 0,018 ( $p<0,05$ ) yang mana diartikan ada hubungan yang signifikan antara umur pekerja dengan terjadinya kecelakaan kerja. Menurut Grandjean dalam Handayani dkk (2010) menyatakan bahwa kemampuan fisik laki-laki dan perempuan akan tercapai secara maksimal pada usia 25-35 tahun dan seiring bertambahnya usia kemampuan tersebut akan terus menurun ${ }^{16}$.

Pekerja yang berusia muda masih punya semangat dan ambisi yang tinggi untuk menunjukkan hasil kerja yang baik oleh karena itu, pekerja yang berusia muda berusaha menghindari kecelakaan ringan dengan menjaga produktivitas dan kinerja dalam bekerja. Tetapi, sikap kecerobohan dan sikap tergesa-gesa juga ada di dalam diri pekerja usia muda yang mana sikap ini sering menimbulkan terjadinya kecelakaan kerja. Sebaliknya, pekerja berusia tua rentan mengalami kecelakaan kerja karena penurunan kondisi fisik dan penurunan tingkat kewaspadaan terhadap kecelakaan di tempat kerja karena merasa sudah terbiasa dan menyepelekan bahaya yang muncul ${ }^{17}$.

Sebagian besar responden di penelitian ini berusia kurang dari 35 tahun atau golongan usia muda. Responden dengan cedera kerja kebanyakan dialami oleh usia tua yaitu lebih dari sama dengan 35 tahun. Namun, hasil dari data penelitian didapatkan bahwa kategori usia tua maupun usia muda yang pernah mengalami kecelakaan kerja memiliki selisih persentase tidak jauh berbeda yaitu sebesar $6,4 \%$ dengan usia tua pernah kecelakaan kerja $(66,7 \%)$ dan usia muda pernah kecelakaan kerja $(60,3 \%)$.

Artinya kecelakaan kerja tidak dipengaruhi usia. Dapat disimpulkan bahwa kecelakaan kerja dapat terjadi pada pekerja usia muda maupun usia tua. Kecelakaan kerja berisiko terjadi pada usia tua dikarenakan kondisi fisik yang sudah mulai menurun seperti berkurangnya konsentrasi saat bekerja, merasa mudah lelah, berkurangnya fungsi indera penglihatan dan pendengaran. Pekerja muda juga berisiko mengalami kecelakaan kerja karena memiliki sikap yang cenderung gegabah, kurang berhati-hati dan terburu-buru dalam bekerja. 


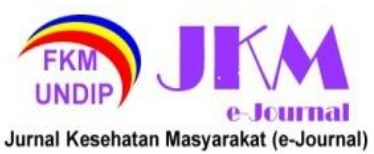

\section{Hubungan antara Pengetahuan K3 dengan Kecelakaan Kerja}

Hasil pada penelitian ini sesuai dengan penelitian Kurniawan, Bina \& Ekawati pada tahun 2018 yaitu ada hubungan yang signifikan antara pengetahuan dengan kecelakaan kerja karena $p$-value 0,014. Pada penelitian tersebut, responden berpengetahuan kurang akan berisiko mengalami kecelakaan kerja daripada responden berpengetahuan cukup maupun baik ${ }^{18}$. Hasil penelitian ini juga sesuai dengan penelitian Meinita tahun 2015 yaitu terdapat hubungan antara tingkat pengetahuan dengan kecelakaan kerja sebab $p$-value $0,000{ }^{19}$

Berdasarkan teori, hasil penelitian ini sesuai dengan teori kecelakaan kerja Frank E. Bird yaitu faktor manusia menjadi penyebab dasar dari kecelakaan di tempat kerja salah satunya pengetahuan yang rendah 20 . Green (2005) juga mengatakan pengetahuan jadi bagian penting dalam mendorong motivasi seseorang untuk bertindak ${ }^{17}$. Notoatmodjo (2007) menyatakan perilaku seseorang terbentuk dari peran penting pengetahuan ${ }^{21}$. Pengetahuan K3 yaitu pemahaman pekerja terhadap bahaya dan risiko di lingkungan kerja yang memiliki potensi mengakibatkan cedera maupun kerusakan ${ }^{22}$.

Menurut penelitian Kalalo, Kaunang dan Kawatu tahun 2016, pekerja yang memiliki tingkat pengetahuan tinggi akan menyadari bahwa ada kemungkinan munculnya risiko dalam bekerja maka mereka akan bekerja sesuai dengan prosedur kerja dan memahami bahaya yang ada di sekitar area kerja. Pekerja yang memiliki pengetahuan baik cenderung hendak berprilaku baik serta selalu berupaya menjauh dari kecelakaan di tempat kerja. Begitupun kebalikannya, jika pekerja berpengetahuan kurang maka biasanya tidak memedulikan bahaya di sekitar karena tidak tahu risiko yang akan diterima ${ }^{23}$.

Dalam penelitian ini mayoritas pekerja memiliki pengetahuan yang rendah mengenai K3 karena pekerja belum memahami betul bahwa penting untuk menjaga keselamatan dan kesehatan selama bekerja. Pekerja belum sepenuhnnya mengetahui bahaya yang mungkin timbul, tujuan dari $\mathrm{K} 3$, dan faktor penyebab kecelakaan kerja karena mereka hanya bekerja tanpa menyadari risiko yang akan diterima. Edukasi dengan pemberian materi K3 pada pekerja menjadi dasar untuk meningkatkan pengetahuan mereka melalui program K3 seperti toolbox meeting. Pekerja yang telah memahami K3 dimaksudkan agar kecelakaan kerja dapat diminimalkan.

\section{Hubungan antara Pengawasan K3 dengan Kecelakaan Kerja}

Hasil pada penelitian ini sesuai dengan penelitian Ashari pada tahun 2019 menunjukkan adanya hubungan antara pengawasan dengan kecelakaan kerja sebab $p$-value $0,000{ }^{24}$. Hasil penelitian ini juga didukung penelitian Anshari \& Azkha tahun 2017 dimana antara pengawasan dengan kecelakaan kerja juga ada hubungan yang bermakna. Pada penelitian tersebut, kecelakaan kerja lebih banyak terjadi pada pengawasan yang kurang baik daripada pengawasan yang baik ${ }^{25}$.

Berdasarkan teori, hasil penelitian ini sesuai dengan teori kecelakaan kerja Frank E. Bird yaitu faktor pekerjaan menjadi penyebab dasar dari kecelakaan di tempat kerja salah satunya pengawasan 20 . Berdasarkan teori, hasil penelitian ini sesuai dengan teori kecelakaan kerja Frank E. Bird yaitu faktor pekerjaan menjadi penyebab dasar dari kecelakaan di tempat kerja salah satunya pengawasan ${ }^{20}$. Pengawasan K3 merupakan pemantauan kegiatan pekerja dan dilakukan secara rutin untuk meminimalisasi adanya tindakan maupun kondisi tidak aman yang mungkin dapat menimbulkan kecelakaan di tempat kerja serta agar segera dilakukan perbaikan ${ }^{26}$. Peraturan Pemerintah RI No 50 Tahun 2012 tentang SMK3 mengatakan bahwa "Dilakukan pengawasan untuk menjamin bahwa setiap pekerjaan dilaksanakan dengan aman dan mengikuti prosedur dan petunjuk kerja yang telah ditentukan" 27. Dengan begitu, pengawasan mampu memotivasi pekerja untuk bekerja dengan benar sesuai prosedur dan proses kerja.

Dalam penelitian ini hasil data yang diperoleh lebih dari separuh pekerja memiliki persepsi pengawasan yang rendah terhadap K3 karena pekerja merasa tidak diawasi saat bekerja dan tidak ada tekanan untuk melakukan pekerjaan dengan hati-hati. Rendahnya pengawasan K3 akan mengakibatkan pekerja bertindak ceroboh, cenderung tidak peduli pada bahaya yang ada di sekitar, tidak patuh terhadap prosedur dan peraturan kerja dan merasa bebas dengan bertindak sesuka hati seperti melakukan tindakan tidak aman saat bekerja. Hal ini akan meningkatkan risiko terjadinya kecelakaan kerja. Sebaliknya, jika pengawasan K3 terhadap pekerja tinggi, maka pekerja akan selalu merasa diawasi, cenderung berhati-hati dan bekerja sesuai prosedur kerja. Peran pihak K3 sangat penting untuk meningkatkan 


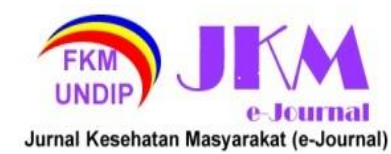

pengawasan terhadap pekerja, agar pekerja merasa aman dapat bekerja dengan baik.

\section{Hubungan antara Unsafe Act dengan Kecelakaan Kerja}

Hasil pada penelitian ini sesuai dengan penelitian Irawati pada tahun 2018 menunjukkan adanya hubungan antara unsafe action dengan kejadian kecelakaan kerja karena $p$-value $0,000{ }^{28}$. Hasil penelitian ini pun juga didukung oleh penelitian Sumairawan tahun 2019 yaitu antara unsafe act dengan kecelakaan kerja terdapat hubungan karena $p$ value didapatkan 0,018 . Pada penelitian tersebut, bentuk unsafe act yang sering dilakukan responden adalah terburu-buru dalam bekerja, barang hasil pekerjaan ditumpuk/tidak diletakkan pada tempatnya, bercanda dan mengganggu karyawan lain, melempar hasil kerjaan serta mengantuk saat bekerja ${ }^{29}$.

Hasil penelitian ini sesuai dengan teori domino Heinrich yaitu tindakan tidak aman yang dilakukan oleh seseorang menjadi penyebab langsung dari kecelakaan kerja ${ }^{30}$. Heinrich mengatakan kecelakaan kerja lebih banyak disebabkan karena unsafe act daripada unsafe condition yaitu sebesar $88 \%$ 14. Teori kecelakaan kerja Frank E. Bird juga menyebutkan hal yang serupa, bahwa penyebab utama kecelakaan kerja berasal dari unsafe act dan unsafe condition ${ }^{20}$. Tindakan berbahaya bisa menimbulkan kecelakaan kerja pada pekerja maupun orang lain yang ada di sekitarnya ${ }^{31}$.

Penelitian ini diperoleh hasil adanya hubungan antara unsafe act dengan terjadinya kecelakaan kerja. Hasil observasi yang telah dilakukan peneliti didapatkan masih cukup banyak dijumpai pekerja sewaktu bekerja melakukan unsafe act diantaranya merokok, menggunakan APD dengan tidak benar dan tidak layak, bekerja dengan tidak fokus, tidak hati-hati dan terburu-buru, membuang sampah sembarangan, serta bercanda saat bekerja. Maka dapat disimpulkan, unsafe act menjadi bagian penyebab terjadinya kecelakaan kerja. Upaya yang bisa dilakukan untuk meminimalkan kecelakaan kerja akibat tindakan tidak aman adalah dengan meningkatkan pengawasan bagi pekerja serta memberikan edukasi mengenai pentingnya K3 dan bekerja sesuai prosedur kerja.

\section{Hubungan antara Unsafe Condition dengan Kecelakaan Kerja}

Hasil pada penelitian ini sesuai dengan penelitian Ulva \& Restipa pada tahun 2019 menunjukkan terdapat hubungan antara unsafe condition dengan kejadian kecelakaan kerja karena $p$-value $0,006{ }^{32}$. Hasil penelitian ini juga didukung oleh penelitian Ramdan \& Handoko tahun 2016 dimana antara unsafe condition dengan kecelakaan kerja terdapat hubungan sebab $p$-value 0,026 . Pada penelitian tersebut, pekerja lebih sering bekerja pada kondisi tidak aman seperti kurangnya kerapihan di area kerja, tidak layaknya APD yang digunakan, dan kurangnya sistem peringatan ${ }^{5}$.

Hasil penelitian ini sesuai dengan pendapat Suma'mur (2009) yaitu unsafe condition adalah suatu kondisi fisik dimana terdapat bahaya di lingkungan kerja dan secara langsung bisa menimbulkan terjadinya kecelakaan 33. Menurut teori Heinrich, 10\% kecelakaan kerja disebabkan oleh unsafe condition ${ }^{14}$. Teori kecelakaan kerja Frank E. Bird menyebutkan sebab utama kecelakaan kerja ialah unsafe condition selain dari unsafe act. Teori tersebut juga menyebutkan bahwa unsafe condition merupakan suatu kondisi lingkungan kerja dimana perlengkapan material, serta proses kerja tidak berpedoman pada keselamatan kerja ${ }^{20}$.

Penelitian ini diperoleh hasil adanya hubungan antara unsafe condition dengan terjadinya kecelakaan kerja. Hasil pengamatan yang sudah peneliti lakukan, ditemukan masih cukup banyak pekerja yang bekerja pada kondisi tidak aman seperti material dan peralatan berserakan, adanya genangan air di sekitar area kerja, kabel yang menghalangi akses jalan, tidak adanya tempat sampah, lantai berlubang tanpa peringatan serta kabel listrik yang berantakan dan terkelupas. Dapat disimpulkan, unsafe condition jadi bagian penyebab dari terjadinya kecelakaan di tempat kerja. Untuk meminimalisasi hal tersebut, yang bisa dilakukan adalah peninjauan kembali terhadap area kerja dan menyarankan semua pekerja untuk merapikan bahan material jika telah selesai bekerja.

\section{KESIMPULAN}

Penelitian yang telah dilakukan pada pekerja Proyek Pembangunan Gedung di PT. $X$ Tahun 2020 dapat disimpulkan bahwa sebagian besar pekerja $(62,4 \%)$ pernah mengalami kecelakaan kerja. Mayoritas pekerja $(67 \%)$ berusia muda. Kebanyakan pekerja (56\%) memiliki pengetahuan K3 yang rendah. Lebih dari separuh pekerja $(51,4 \%)$ memiliki persepsi terhadap rendahnya pengawasan K3. Hampir separuh dari pekerja 


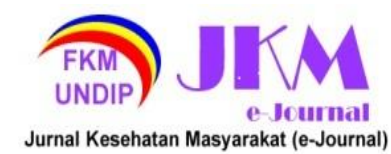

(49,5\%) melakukan tindakan tidak aman dan bekerja pada kondisi tidak aman.

Terdapat hubungan antara pengetahuan K3 ( $p$-value 0,003$)$, pengawasan K3 ( $p$-value $0,001)$, unsafe act $(p$-value 0,002$)$ dan unsafe condition ( $p$-value 0,000$)$ dengan kecelakaan kerja. Namun tidak terdapat hubungan antara usia dengan kecelakaan kerja ( $p$-value 0,662$)$.

\section{SARAN}

$\begin{array}{ccc}\text { Saran atau rekomendasi untuk } \\ \text { penelitian } & \text { selanjutnya } & \text { adalah }\end{array}$ mengembangkan dan menambah variabel yang tidak diteliti di dalam penelitian ini seperti sosialisasi K3, masa kerja, housekeeping, kebisingan dan lainnya serta mencari faktor dominan dari penyebab kecelakaan kerja di sektor konstruksi.

\section{UCAPAN TERIMA KASIH}

Penelitian ini tidak luput dari segala bantuan dan arahan berbagai pihak. Terutama peneliti mengucapkan terima kasih kepada PT. $X$ yang telah bersedia memberikan kesempatan kepada peneliti untuk melakukan penelitian serta HSE dan para pekerja yang telah bersedia berkontribusi dalam pelaksanaan penelitian.

\section{DAFTAR PUSTAKA}

1. Sumito. Safety Construction: Komitmen dan Konsistensi Terapkan SMK3. BPSDM Kementerian Pekerjaan Umum dan Perumahan Rakyat. 2018 Apr;4-5.

2. Ditjen Bina Konstruksi Kementerian PUPR. Cegah Kecelakaan Kerja Konstruksi, Kementerian PUPR Latih Tenaker yang Bekerja di Konstruksi Jalan Layang [Internet]. 2018. Available from:

http://binakonstruksi.pu.go.id/editor/artik el-berita/765-cegah-kecelakaan-kerjakonstruksi,--kementerian-pupr-latihtenaker-yang-bekerja-di-konstruksijalan-layang

3. Ditjen Bina Konstruksi Kementerian PUPR. Pemerintah Genjot Sertifikasi Ahli K3 [Internet]. 2019. Available from: http://binakonstruksi.pu.go.id/editor/artik el-berita/913-pemerintah-genjotsertifikasi-ahli-k3-2

4. Syafiq U, Perdhana MS. Kecelakaan Kerja pada Perusahaan Konstruksi: Sebuah Telaah Literatur. DIPONEGORO J Manag. 2018;7(23373792):1-9.

5. Ramdan IM, Handoko HN. Kecelakaan Kerja Pada Pekerja Konstruksi Informal di Kelurahan " $X$ " Kota Samarinda. J MKMI. 2016;12(1):1-6.

6. Khosravi $\mathrm{Y}$, Asilian-Mahabadi $\mathrm{H}$, Hajizadeh E, Rangi-Hassanzadeh N, Bastani $\mathrm{H}$, Behzadan AH. Factors Influencing Unsafe Behaviors and Accidents on Construction Sites: A Review. Int J Occup Saf Ergon. 2014;20(1):111-25.

7. Wirahadikusumah RD, Ferial F. Kajian Penerapan Pedoman Keselamatan Kerja pada Pekerjaan Galian Konstruksi. J Tek Sipil. 2005;12(2):53-62.

8. ILO. Meningkatkan Keselamatan dan Kesehatan Pekerja Muda. 1st ed. Jakarta, Indonesia: ILO Katalog; 2018.

9. ILO. Safety and Health at The Heart of The Future of Work: Building on 100 Years of Experience. 1st ed. Geneva, Switzerland: ILO Cataloguing; 2019.

10. BPJS Ketenagakerjaan. Angka Kecelakaan Kerja Cenderung Meningkat, BPJS Ketenagakerjaan Bayar Santunan Rp 1,2 Triliun [Internet]. $2019 . \quad$ Available from: https://www.bpjsketenagakerjaan.go.id/b erita/23322/Angka-Kecelakaan-Kerja-

Cender

11. Restuputri DP, Sari RPD. Analisis Kecelakaan Kerja dengan Mengggunakan Metode Hazard and Operability Study (HAZOP). J IIm Tek Ind. 2015;14(1):24-35.

12. Notoatmodjo S. IImu Kesehatan Masyarakat Prinsip-Prinsip Dasar. Jakarta: Rineka Cipta; 2003.

13. Sucipto CD. Keselamatan dan Kesehatan Kerja. Yogyakarta: Gosyen Publishing; 2014.

14. Triyono MB. Keselamatan dan Kesehatan Kerja (K3). Yogyakarta: Universitas Negeri Yogyakarta; 2014.

15. Juliana, Purna IN, Aryana IK. FaktorFaktor yang Berhubungan Dengan Kecelakaan Kerja Pada Pengrajin Gong di Dusun Tihingan, Kabupaten Klungkung. J Kesehat Lingkung. 2018;8(2):82-91.

16. Handayani EE, Wibowo TA, Suryani D. Hubungan Antara Penggunaan Alat Pelindung Kerja Pada Pekerja Bagian Rustic di PT Borneo Melintang Buana Export Yogyakarta. J KES MAS. 2010;4(3):144-239.

17. Siregar DIS. Faktor-Faktor yang Berhubungan dengan Kecelakaan Ringan di PT Aqua Golden Mississippi Bekasi Tahun 2014. Universitas Islam 


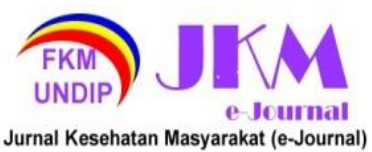

Negeri Syarif Hidayatullah; 2014.

18. Kurniawan $\mathrm{Y}$, Kurniawan B, Ekawati. Hubungan Pengetahuan, Kelelahan, Beban Kerja Fisik, Postur Tubuh Saat Bekerja, dan Sikap Penggunaan APD dengan Kejadian Kecelakaan Kerja. J Kesehat Masy. 2018;6(4):393-401.

19. Meinita TSP. Analisis Faktor yang Berhubungan Dengan Kecelakaan Kerja di CV. Prima Logam Tegal. Universitas Negeri Semarang; 2015.

20. Sujoso ADP. Dasar-Dasar Keselamatan \& Kesehatan Kerja. Jember: UPT Penerbitan UNEJ; 2012.

21. Notoatmodjo S. Promosi Kesehatan \& IImu Perilaku. Jakarta: Rineka Cipta; 2007.

22. ILO. Keselamatan dan Kesehatan Kerja Keselamatan dan Kesehatan Sarana untuk Produktivitas. 1st ed. Jakarta: International Labour Organization (ILO); 2013.

23. Kalalo SY, Kaunang WPJ, Kawatu PAT. Hubungan Antara Pengetahuan Dan Sikap Tentang K3 Dengan Kejadian Kecelakaan Kerja pada Kelompok Nelayan di Desa Belang Kecamatan Belang Kabupaten Minahasa Tenggara. J IIm Farm. 2016;5(1):244-51.

24. Ashari GN. Faktor-Faktor yang Berhubungan dengan Kejadian Kecelakaan Kerja pada Pekerja Proyek Pembangunan The Park Mall Sawangan di Area Mezzanine PT. PP Presisi Tbk Tahun 2019. Universitas Pembangunan Nasional Veteran Jakarta; 2019.

25. Anshari LH, Azkha N. Faktor-Faktor yang Berhubungan dengan Kecelakaan Kerja pada Karyawan PT Kunanggo Jantan Kota Padang Tahun 2016. In: "Peran Tenaga Kesehatan dalam Pelaksanaan SDGs." Padang; 2017. p. 235-41.

26. Tampubolon LJ. Efektivitas Pengawasan Keselamatan dan Kesehatan Kerja Oleh Dinas Sosial dan Tenaga Kerja Kabupaten Sidoarjo sebagai Upaya Mewujudkan Budaya K3. Kebijak dan Manaj Publik. 2015;3(3):3443.

27. Peraturan Pemerintah. Penerapan Sistem Manajemen Keselamatan dan Kesehatan Kerja. Indonesia: Peraturan Pemerintah Republik Indonesia; 2012.

28. Irawati I. Hubungan Unsafe Condition dan Unsafe Action dengan Kecelakaan Kerja (Kemasukan Gram pada Mata) Pekerja Pengelasan. $\mathrm{J}$ Kesehat.
2018;9(2):89-94.

29. Sumairawan BR. Hubungan Unsafe Act dan Unsafe Condition dengan Kecelakaan Kerja pada Pekerja di Bagian Produksi CV. Gerimis Garment Jakarta Tahun 2019. Universitas Pembangunan Nasional Veteran Jakarta; 2019.

30. Friend MA, Kohn JP. Fundamentals of Occupational Safety and Health. 4th ed. United States of America: Government Institutes; 2007.

31. Suma'mur. Keselamatan Kerja dan Pencegahan Kecelakaan. Jakarta: PT. Gunung Agung; 2014.

32. Ulva F, Restipa L. Hubungan Tindakan kerja dan Kondisi Kerja dengan Kecelakaan Kerja pada Pekerja Bagian Tiang Besi di PT. X Kota Padang Tahun 2017. J Keperawatan Abdurrab. 2019;3(1):44-50.

33. Suma'mur. Higiene Perusahaan dan Kesehatan Kerja. Jakarta: PT. Gunung Agung; 2009.
